\title{
People with Psychological/Behaviour/Mental Problems
}

\section{Opinion}

\section{Paul Wilkins* \\ Public Relations and Communications, UK}

*Corresponding author: Paul Wilkins, UK

Submission: 悳 February 27, 2018; Published: 悳 March 20, 2018

\section{Opinion}

The thing in the whole world that is getting everyone worldwide worse health wise day after day, especially, though not only, people with psychological/behaviour/Mental problems is the inexplicit unnatural title 'DOCTOR' being used day after day

\section{To give evidence of this I'd like you to put yourself in the} following 2 positions

a) One day you are at home feeling very stressed, upset, depressed, lonely, mentally upset not knowing what to do. A friend of yours by chance is walking down your street and by chance when passing your house thought 'Oh I haven't see such and such for a while, I'll nip and see how he/she is getting on'. This friend comes knocking on your door, coming not to your personal expectation, asking how you are? Giving you the chance to naturally speak out and get off your mind what your personal psychological problems have been thanks to someone contacting you and asking, not you having to think about contacting someone to do so.

b) On another day you are again at home feeling very stressed, upset, depressed, lonely, mentally upset not knowing what to do. With no-one contacting you for ages to help you naturally share your problems, get them off your mind, you're getting so upset you feel that you need to do something before you get even worse. The only option you have is to ring up and make a normal/ or if necessary emergency appointment to see a person with an inexplicit title of Doctor, and by yourself make unnatural plans of what to say to him or her with a 'title' explicitly meaning what?

Which of the above 2 situations would you prefer to be in? If you haven't guessed already, most people I've put in these situations so far have opted to situation 1 .

One way to make psychological situation 1 more applicable to people, without having to send people to their house when they're not expected, is to change the silly unexplicit title 'doctor' to something more naturally thought explict such as 'health consultant', 'health adviser' , 'health assistant' etc

With a reference to a 'health consultant' I'll think naturally about going to see them for a 'consultation about my health'.

With a reference to a 'health adviser' i'll think naturally about going to see them for some 'advice about my health'.

With a reference to a 'health assistant' i'll think naturally about going to see them for some 'assistance with my health'.

With reference to a 'doctor' i can think of this word explicitly/ naturally saying what?

Or is it an unexplicit/unnatural confusing 'title'? bringing health problems forward more!
Creative Commons Attribution 4.0 International License

For possible submissions Click Here

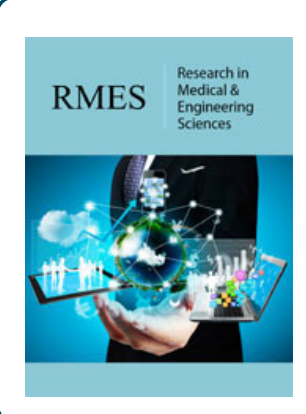

Research in Medical \& Engineering Sciences

Benefits of Publishing with us

- High-level peer review and editorial services

- Freely accessible online immediately upon publication

- Authors retain the copyright to their work

- Licensing it under a Creative Commons license

- Visibility through different online platforms 